\title{
BEHAVIOUR PROBLEM: THE CASE OF 'YANDABA IN KANO, NIGERIA
}

\section{Dr. USMAN DA’U ALIYU}

\begin{abstract}
The paper adopted both theoretical and positioned approach to the study of the 'Yan Daba phenomenon in Kano. An up-to-date data on the prevalence and causes of the problem of the cohorts was collected using a questionnaire (QSPD) that was designed by this writer. The questionnaire was administered to the officials of the government agencies directly dealing with the urban group. The paper concludes that, the delinquent behaviour is a product of the socio-economic predicaments facing the common man, which can be treated through religious and vocational counseling.
\end{abstract}

\section{Introduction}

'Daba' is a Hausa word that refers to a 'group' or 'gang', meaning group bounded by common interest, trade or profession that converge in a particular place to carry out their activities (Abdullahi, 2001, Dan Asabe, 1991). Later on, 'Daba' assumed a new meaning when particular age groups, started to engage in antisocial behaviour and acts of delinquency. Therefore, the social deviants that are involved in aggressive and criminal activities are referred to as 'Yan Daba. In the context of this paper, the 'Yan Daba are interchangeably referred to as: cohorts, urban gangs or delinquents.

The 'Yan Daba phenomenon is a behaviour problem because it deviates from the norm, and constitutes a nuisance to the general public in the City of Kano. In spite of the significance of the problem, an inadequate attention was devoted to it by scholars, resulting to scarcity of literature in the area. Hence, a data collection instrument named "Questionnaire on the Prevalence and Causes of the problem of 'Yan Daba" (QPCD) was designed by this writer. The questionnaire was administered to officials of government agencies directly dealing with the delinquents namely the Police, Youth Development Department and Office of the Special Adviser to the Governor of Kano State on Metropolitant Affairs.

The paper traced the history of the problem in Kano, reviewed the available literature with a view to seeing the nature and approaches adopted in handling the problem at the global level. Also contained are the characteristics of the delinquents, causes and solutions to the problem as gathered through the data collection instrument (QPCD).

\section{Historical Background of the 'Yan Daba}

A study (Dan Asabe, 1991) into the history of 'Yan Daba in Kano City revealed that it has taken many forms and shapes with the socio-economic and political changes that characterized the ancient city within the last fifty years. 
The origin of the phenomenon was traced to the political patterns of 1954-1966, when the principal opposition party in Kano, namely the 'Northern Elements Progressive Union' (NEPU) felt threatened and was not adequately protected by the Native Authority Police, this led to the recruitment of local hunters as thugs or vanguards to provide protection to the opposition leaders. The other political parties also recruited their private armies later, leading to clashes between the rival groups in subsequent electoral campaigns. This was terminated with the first military take-over in the country, and the vanguards were reintegrated into the society.

The restoration of the democratic rule in the Second Republic, beginning with the suspension of the ban on partisan politics in 1978 saw the reemergence of the vanguards. The politicians as usual recruited thugs, and were found to be more sophisticated and stubborn, because some of them have a measure of Western education and indulge in drug abuse. More so, the sponsors of the urban gangs are wealthier due to the relative economic prosperity in Nigeria. This development was also checked with the second coming of the military at the end of the year 1983.

Dan Asabe (1991) and Indabawa (1988) further revealed that the 'Yan Daba phenomenon, from 1983 and beyond was associated with crime, and refers to a group of youngsters between the ages of 10 and 30 years with no visible means of livelihood and often engage in criminal activities e.g. rape, drug abuse, homicide, killing for hire, armed robbery, gang war, theft etc.

The activities of the gangs got a boost with the inception of Forth Republic in 1999, as they are being patronized by politicians. The art of thuggery is been professionalized in that politicians contract the services of the gangs through coordinators; where the services required can be specified either to coerce, soften of disorganize political opponents/rallies or simply to fill-up the places at the time of rallies, (Indabawa, 2002). It is the type of service requested that determines the number of the participants and price to be paid. This is in addition to the routine criminal activities (Indabawa, 2002). Efforts were made by the law enforcement agents to deal with the problem, but had only succeeded in suppressing the activities of the urban gangs temporarily. The urban gangs are patronized by politicians and thus thrive during the civilian regime.

\section{Literature Review: The Cohorts}

Adolescents and youth are usually called 'cohorts', referring to young people who are united not by desire to achieve some goal through struggle, but united by exposure to a given set of cultural conditions i.e. influenced in particular ways by historical event leading to a kind of deviant behaviour (Beilher, 1984:503). In the American society, such historical events as the Second World War, American involvement in Vietnam and the impact of inflation, high rates of unemployment etc have radically affected the values and behavioural patterns of the young people.

On the same note, we can rightly attribute the ever-changing behaviour patterns of the young people in Kano City, including the 'Yan Daba phenomenon, to the relatively new socio- 
economic and political developments in the country. Last (1991) observed that the Structural Adjustment Programme (SAP) has adversely affected the lives of the ordinary people, in that it has significantly increased the rate of poverty e.g. the inability of parents to adequately cater for their families resulting in moral laxity; marriages are postponed for want of money, and casual jobs are low paid and scarce. Similarly, some of the sons of the rich were spoiled at a tender age, and when the parents can no longer satisfy their irrational demands, the children tend to go wild.

Furthermore, many more of the young people in Kano City are attending westem schools; hence, there are a lot of primary and secondary school graduates and dropouts. The public service has no place for this category of young people, the failure of the educational system in Nigeria to cater for children that cannot further their education beyond the Junior Secondary School level has compounded the problem (Aiyepeku, 1989). Moreso, the traditional practices of initiating children into their family trades or vocation is fast dying. This large army of unemployed and deprived young people are readily available for use by willing politicians as thugs in the civilian era and can easily be tempted into crime (Aliyu, 2002). Most of the urban gangs make a living out of this illegal activity.

The socio-economic and political conditions highlighted above, showed that the system has endangered the interest of the youngsters and are capable of breeding wild and negative tendencies in the society. They miserable and frustrating plight of the young people is what makes them to turn against the larger society by being aggressive and violent.

The unrestricted flow of information e.g. films and novels, particularly the foreign, the themes of which are either crime or tragedy have contributed to the growing culture of crime and violence among young people. Closely related with that is the more or less indiscriminate importation, production and retailing of hard drugs and intoxicating substances in Nigeria which has undoubtedly contributed negatively to the problem (Dan Asabe 1991; Inadabawa 1988).

\section{Etiology of Aggressive Disorders}

A review of studies into the antecedents of aggressive disorders by Wells and Forehand (1985) revealed that there are multiple factors under-laying such antisocial behaviour, they include the following:

\section{Constitutional and biological predisposing influence}

a) Child temperament: Persistent manifestation of aggressive behaviour in many children at an early age suggests the tendency for an aggressive behaviour (Larbar \& Patterson, 1981).

b) Medical view: Association was found between delinquent aggressive behaviour and accidents and injuries among delinquent girls (Shanok and Levis, 1981), symptoms of psychomotor epilepsy, minor neurological impairment signs (Lewis, Sheak, Pinions \& Glaser, 1979), and a causal relationship between temporal globe epilepsy and violence in adults (Delgado-Escueta et al, 1981). 
c) Social Influence: Wells and Forehand (1985:234) reported that a number of studies have identified social context variables that are related to the development and maintenance of aggressive/delinquent behaviour. For instance, those anti social behaviours were found to be associated with socio-economic status, large sibling size and broken homes (Robins, 1966; Butter, Tizard, Whitmore, 1970, West and Farrington, 1973). Parents of the delinquents were found to be less adequate in overall social adjustment e.g. less education, less use of available health services and less ability to obtain and hold a job (Robins, 1979). However, according to Wells and Forehand (1985) the relationship between family size and aggressive behaviour is unclear.

d) Family Patterns: A naturalistic observation of parenting behaviour revealed, that parents of aggressors give significantly more command, vague and threatening commands and criticize their children at a higher rate (Rogers, Forehand \& Griest, 1981; Wells \& Forehand, 1981). The owing variables were found to be common among the parents of delinquent children (Glueck \& Glueck, 1972); a permissive, negative, rejecting and indifferent maternal behaviour towards a boy results in relatively more aggressive and hostile behaviour at adolescence (Olweus, 1980).

e) Marital discord and conflict: Mixed results were found in the relationship between marital dissatisfaction in parents and aggressive behaviour in children, significant relation was found in others (e.g. Griest, Forehand \& Wells, and McMahon, 1980).

\section{Parent Psychopathology}

Wells and Forehand (1985:238) reported the result of works that looked into the relationship between parent's psychopathology and aggression. Significant correlation was found between father's elevated MMPI scores and observed deviance level of the target child (Johnson \& Lobitz, 1974); mothers of 'stealer' (i.e. the under socialized, aggressive and non aggressive conduct disorders) had MMPI peaks psychopathic deviate, hypomania and schizophrenia; whereas mothers of aggressive children showed elevation on the scale indicating depression, rigidity and social introversion (Patterson, 1980).

The studies reviewed as reported by Wells and Forehand (1985), are evidences of the significance of a wide range of social, biological etiology of aggressive behaviour in children.

\section{Classifications of Aggressive Behaviour}

Childhood psychopathological disorders are classified using the: Diagnostic and Statistical Manual of Mental Disorders or the DSM3 third edition (American Psychiatric Association, 1980; cited in Wells \& Forehand, 1985). There are two major types of aggressive behaviour disorders relevant to children in DSM3, namely the conduct disorders and oppositional disorders.

The conduct disorders category includes four subtypes: under socialized aggressive, under socialized-non aggressive, socialized aggressive, and socialized-non aggressive. Therefore, 
the four subtypes vary along two dimensions i.e. aggressive-non aggressive and socializedunder socialized (Wells \& Forehand, 1985: 219).

A child identified with any of the aggressive subtypes is characterized by a persistent aggressive conduct in which the right of others are violated e.g. physical violence against persons or objects, or even theft involving confrontation with his/her victim. On the other hand, the non-aggressive conduct disorders involve rule violations, such as truancy, substance abuse, lying and stealing which are neither violent nor confrontational. The socialized-under socialized dimension refers to the child's capacity for feelings of guilt and attachment to other persons (Well \& Forehand, 1985:220). A child identified with any of the socialized subtypes shows evidence of regard of and attachment to one or more peer-group, and or shows remorse for wrongdoing. However, the under socialized persons were found to have failed to establish a normal degree of affection, empathy, or bond with others.

The second major syndrome of aggressive behaviour in children is oppositional disorder, where the individuals manifest disobedient and provocative opposition to authority figures, primarily the parents and sometimes extending to teachers and other children as well. The essential behavioural characteristics are temper, tantrums, argumentativeness, stubbornness and violation of minor rules. The diagnosis is not made for children who violate the basic rights of others or break major social norms.

Wells and Forehand (1985: 225) reported a few factor analytic studies (Quay, 1964; Wolff, 1967) that found some evidence for at least three potential dimensions of boys institutionalized for delinquent behaviour, which are labeled socialized sub-cultural delinquents, un-socialized-psychopathic delinquents and disturbed neurotic delinquents.

In view of the foregoing, the cohorts in Kano can be classified as both under socialized, aggressive and non aggressive delinquents because they are characterized by such antisocial behaviours as truancy, drug abuse, stealing, rape, robbery, fighting and general disregard for the sensitivities of others.

\section{Sub-Cultural Theories of Delinquency}

Three divergent approaches were adopted by the sub-cultural theorists. Miller (1985) cited in Lee (1971:285) hypothesized that the child is indoctrinated with the criminal ethics at an extremely early age, and he is never given the opportunity to develop the normal societal behaviour. From this perspective, for example, the reason why there is high rate of damage to equipment and facilities in lower-class schools is because of their culture that is devoid of respect for private property. To reform such a child therefore requires him to be "deculturized" and "reculturized" i.e. his internalized self must be changed.

On the same note, Cloward and Ohlin (1961) insists that a delinquent subculture exists, that the behaviour is not totally depended upon the lower-class deviant subculture, but, the delinquent behaviour is caused by a lack of ability to meet the established societal goals through the normal societal means. 
On his part, Cohen (1955) advanced that all children start with essentially the same code of ethics and set of norms. However, upon entering school the middle-class or upper-class which learns that it is entirely possible for him to succeed in school and in life generally. Unfortunately for the lower-class child, once he enters school, he often finds that he is not capable of achieving in school because of a lack of academic background in the home and in the environment; and that, even if he should do well in school it would be difficult for him to achieve fully in society at large because of the financial and social pressures placed upon him by the society and his own immediate culture. The implications of these theories are that the cause of the child's behaviour lies in his own culture and-home; that the child can be reformed only through changing his internalized self; and that the solution of the problem lies in providing equal opportunities to all citizens regardless of their cultural background.

\section{The Alienation Theory:}

The theory holds that the reason why some children become juvenile delinquents is not that their ethical structures are different from conventional ones, but because some of their behaviors are different. The alienation theorists blame the social institutions and society for juvenile delinquency e.g. the student damages the school equipment out of frustration, for the school's failure to meet his needs; therefore behaviour was a response to the school itself.

One alienation theorist (Matza, 1964 cited in Lee, 1971: 286) explained that the values of the dominant culture serve as a deterrent to deviant behaviours. An individual may be alienated (i.e. deprived of the basics of life that are necessary for success) through the process of neutralization. An individual that feels alienated tends to drift i.e. drift out of the conventional code, and commit non-conventional acts by temporality suspending the superego. Therefore, the child has to drift in the first place before delinquency can occur. It follows that to curb the problem of delinquency it is imperative to adequately cater for the needs of the growing child, thereby providing him with security for a worthy living.

Along the same line, the aggressive behaviour was interpreted in the light of the theory of psychoanalysis (Flugel, 1985 cited in Abdullahi, 2001: 16); where individuals manifest aggressive tendencies without being provoked and seem to derive pleasure out of delinquent behaviour; which was attributed to a perennial source of energy rooted in man, which is also independent of any external thwarting or frustration. This is compatible with the description of the gangs in Kano as individuals that see 'violence as an end'. In other words, they are aggressive neither because of any apparent provocation nor any visible purpose (Shehu, 2002).

\section{Discussion}

Do any of the theories reviewed above explain the behaviour of the subjects of our study? In the first place the theories emphasized socio-economic status. It is a fact that social stratification exists among the Kano community, where the people are grouped into the rulers (hereditary and non hereditary), the learned (Western and Islamic), the wealthy and the commoners (Jalingo, 1986). But, this categorization does not breed class antagonism due to the effects of the cultural beliefs and practices, Jalingo (1986) further revealed. The fact that 
some of the urban gang are from the "upper class" makes it inappropriate to attribute the behaviour problem solely to socio-economic inequalities. Nonetheless, one cannot totally ignore socio-economic variable as a factor for the delinquent behaviour, because majority of the delinquents are of humble background. The prevalence of delinquent behaviour among the poor supports the alienation theory. It is also possible that the delinquent behaviour many be due to the influence of internal energies found in the individuals (Flugel, 1985 cited in Abdullahi, 2001).

\section{Assessment}

Assessment of aggressive behavior disorders of children should take into account the primary features of the disorder as well as associated features that may be present. Well and Forehand (1985:24) suggested the use of clinical interview that is relevant to the description and diagnosis of home problems; interview with the parent and teacher, teacher-recorded behavior, and behavioural observations by independent observers which will reveal the classroom behavior; and assessment of family's community interactions using such instruments as rating scales e.g. Walker Behaviour Problem Checklist; Sociometric Ratings, Role Playing Tests and the Behaviour Assertiveness Test for boys.

\section{Treatment}

One of the recommended treatments for deviant behavior was the Parental Behavioural Training Programme (Wells \& Forehand, 1985); the treatment is presented.

One of the Parental Behavioural Training Programmes is the Patterson's Treatment Programme for Children in an older age range, which can be divided into three phases, with progression to each phase contingent upon successful completion of the one before. The phases are presented below.

i. The first phase of treatment focuses on teaching parents the basic concepts and language of social learning theory. Parents are asked to read one of two tests (Patterson. 1975; Patterson \& Guillion, 1968 cited in Wells \& Forehand, 1985, 250) and answer questions on each chapter.

ii. During the second phase, parents are taught to define, track and record behavior and are asked to delineate two deviant and two pro social behaviours of the child. The parents then record these behaviours at home for a three-day period. Daily phone calls to the home occur during this time to prompt parents to collect their data for the day.

iii. In the third phase, parents are trained to develop intervention programme beginning with two or three easily tracked behaviours. A point system is set up where by the child earns and loses point's contingent on positive and negative behaviours respectively. Points are exchanged daily for back-up rewards selected by the child. In addition, parents are taught to use positive social reinforcers, such as verbal labeled rewards for positive behaviours, and to implement a time-out procedure of negative behaviours, thus, the child is earning multiple reinforcers for positive behaviours (e.g. praise and points for compliance) and multiple negative consequences for deviant 
behavior e.g. loss of points and time out for non compliance (Patterson, et. Al. 1975; Wells \& Foreman, 1985:250).

It was observed that the effect of parental timing programmes does not persist, this also applies to the effect of generalization treatment (Wells \& Foreman, 1985:253). In other words, there is no convincing evidence that the various therapeutic treatments have any permanent effect in reducing juvenile delinquency. Grazino \& Bethel-(1983) opined that the inability to purge the individual of delinquent behaviour is a failure on the part of the behavior modification therapist.

\section{Characteristics, Causes and Solution}

The Questionnaire on the Prevalence and Causes of the Problem of 'Yan Daba (QPCD) designed by this researcher was administered to some government officials (Yahaya, Shehu \& Indabawa 2002). The questionnaire covered three main areas namely the biosocial data, socio-economic attributes of the 'Yan Daba and the third portion related to the nature, causes and solutions to the behavior problem. Below are the respective data collected using the said questionnaire (QPCD).

\section{The characteristics of the urban gang are:}

i. Physical: Red-eyed, dark lips, untidy, peculiarly dressed e.g. use of handkerchief as head's cap.

ii. Social: Gregarious, mistrustful of others, secluded (they conduct their activities in isolated hid-outs) but still live with their parents, intra-conflicts, united against common enemies.

iii. Emotional: Disturbed, insecure, aggressive, self-assertive, rebellious against all, instill fear in others; intimidating.

iv. Language usage: Use coded language, use a kind of slang and elongated speech, use of vulgar language.

v. Morality: They are amoral because they deviate from the societal norms, in that they engage in such anti social behaviours as drug abuse, violence, theft and even rape.

vi. Age: Their activities are more pronounced from the age of 17 to 25 years, but their behavior patterns are manifest in potential urban gangs beginning at the age of about 10 years. Thus, adolescents for the majority of the urban gangs and few children and young adults.

Children of about 10 years are either coerced (Shehu, 2002) or lured (Indabawa, 2002) to smoke or buy cigarette for them on one hand, or be enticed with money respectively. Hence, new members are recruited into the gang. As children they serve the purpose of surveillance of the possible places to steal or even rob (Indabawa, 2002). However, the gangs were not known to engage in theft or rape until about the year 1983. Initially, they terrorize people without any reason, with neither the motive to rob nor rape; this is why their violent behavior was referred to as 'violence as end in itself' Shehu (2002) disclosed. 
vii. Education: About $70 \%$ of the members of the gang had either completed primary education or junior secondary education and cannot proceed largely for economic reasons. Others had finished secondary education and hardly do you find one that had finished secondary education and hardly do you find any one that had not attended any form of school.

viii. Socio-economic background: Between $95-98 \%$ of the members of the urban gangs are from the low-economic class where parents are low income earners engaged in some business activities. The rest of the group members are spoiled sons and daughters of the rich and the highly placed.

ix. Sex: About $95-98 \%$ of the group members are males. The balance comes from the female folk. The latter usually cook for their male counterparts, they partake in promiscuity, and expend the money generated in dresses and feeding. The females also move in group, they abhor marriage, and whenever any of them attempts to disengage from the group by way of marrying, the other members tend to thwart the marriage; they can go to the extent of setting the bride's room ablaze, (Indabawa, 2002; Shehu, 2002).

x. Occupation: Some are idle and thrive on crimes, but many are engaged in lawful businesses e.g. petrol hawking, petty trading, tube vulcanizing, pushing hand or wheel barrows, head loading, fishing etc.

xi. Drug abuse: The urban gangs are in the habit of taking various forms of substances e.g. Indian hemp, skudie, fiyafiya (insect killer), sholisho (a type of vulcanizer adhesive substance). They hardly take beer, possibly because of its relative cost and that the former substances are more stimulating. The said substances make them resistant to beatings and relieve them of any sense of guilt (Shehu, 2002).

\section{The Causes of the Urban Gang Phenomenon:}

The causes of the urban gang phenomenon include:

i) Poverty: The economic predicaments facing the nation has made life difficult for the common man; so much that parents can hardly meet the basic requirements of their wives and children and consequently most parents have little or no time for providing the needed moral training to their families. This unfortunate situation exposes the young ones to many temptations and risks.

ii) Broken home: Marital conflicts and divorce are rampant, where this happens the children are usually stranded, which leads them to delinquency. The rate of disharmony among spouses may not be unconnected with the economic misfortunes of the families.

iii) Frustration: The miserable lives of the young people i.e. no dependable means of livelihood, no education, no promising future, these multiple threats to the lives of the youngsters is frustrating, which makes them to go wild, thereby turning against the dominant values.

iv) Lack of socio-economic security: The socio-economic inequalities have left the children of the poor without good education and reliable means of earning for a living, as a result of which you get many drop-outs and unemployed, who are lured into crime as a means of making the two ends meet. 
v) Availability and indiscriminate retailing of hard drugs: This tends to contribute to the wide spread drug abuse (Dan Asabe, 1991; Indabawa 1988). The consumption of hard drugs and intoxicants makes the young people violent and destructive.

\section{Solution to the Problem of the Urban Gang:}

So far the government and people have adopted the following measures in an effort to curb the menace of urban gang:

i) The Police Command in Kano State have been counseling parents on the need to be monitoring the conduct of their children in order to check their excesses. This is being done through the electronic and print media and through the Police-Community Relations Committee meetings. In addition, the Police conduct occasional raids to eradicate the menace of the gangs which forces the latter to go underground.

ii) Some communities have made modest efforts to rehabilitate the urban gangs e.g. in Dan Agundi quarters within Kano City, about 200 delinquents were enrolled into Islamiyya schools and vocational training offered to them with a view to making them responsible and productive citizens.

iii) Efforts were made by Kano State Government through the Special Adviser on Metropolitan Affairs to enlarge the afore-mentioned community initiative named "ANNUR", where each community will organize educational and vocational training programme for the youth, with the view to giving them a sense of belonging and socio-economic security.

iv) The various economic empowerment programmes by State and Federal Governments are capable of alleviating the sufferings of the common-man and thus promoting the economic fortunes of a good number of the people.

v) The proposed extension of the Community Reorientation Committees (CRC) to the ward level in Kano State, where communities will liaise with security agencies, will significantly promote the economic well-being of the people and reduce the rate of delinquency among the youth.

\section{Conclusion}

Comparison between the factors behind aggressive behavior in the literature reviewed (Wells \& Forehand, 1985) on one hand, and the causes of the urban gang behavior problem prevalent in Kano City revealed that the factors can be referred to as 'social influences', because they have a lot to do with the socio-economic background of most of the individuals that indulge in the delinquent behavior. Also, the problem can be attributed partly to what Wells and Forehand (1985) called 'marital discord and conflict' which is largely a product of the uneasy economic atmosphere in most homes within the nation.

As for solution to the problem, the limited success of the therapeutic treatments in controlling delinquent behaviours is evident (Grazino \& Bethel, 1983 cited in Wells \& Forehand, 1985). If the successes of those methods of treating delinquency are partial among Euro-Americans, one can deduce that they are not suitable to our setting largely due to our peculiarities. But the relative success of the community initiative in rehabilitating the urban gangs 
experimented in the City of Kano points to the appropriateness of religious and vocational counselling in handling the problem. Hence, professional psychologists can contribute significantly by critically examining the content of the programme in use, with the view to enriching it, in order to make it more comprehensive and effective. 


\section{References}

Abdullahi, M.I. (2002). "A Study of Psycho-Social Basis of Aggressive, Behaviours of 'Yan Daba and their Implications to Guidance and Counseling". NIJES, Journal of the Department of Psychology, F.C.E. 1 (1): 16-20.

Aiyepeku, T.F. (1989). Colleges \& University Text: 6-3 -3-4 System of Education. Ibadan: NPS Educational Publishers, Ltd.

Aliyu, U.D. (2002). "Fostering Discipline and Stability Through Counseling." Paper to the $26^{\text {th }}$ National Annual Conference of CASSON.

Beilher, R. (1984). Introduction to Child Development. Boston, U.S.A: Houghton Press Ltd.

Dan Asabe, A.U. (1991). "Yandaba: The 'Terrorists' of Kano Metropolitant" Kano Studies, Bayero University, Kano, 85-112.

Graziano, A.M. \& Bethel, D.L (1983). "Failure in Child Behaviour Therapy" p. 406-424 in E.B. Foa. \& Emmelkamp, (eds) Failures in Behaviour therapy. New York: A Wiley-Inter Science Publication, John Wiley \& Sons.

Indabawa, M.A. (1988). 'Yan Daba, "Yan Tauri Da "Yan Daukan Amarya A Kano", Document on the types and solutions to antisocial behavior in Kano, by a staff of WRECA, Water Division, Kano Zone, Kano.

Indabawa, A.S. (2002). "Response to Questionnaire on the Prevalence and Causes of the Problem of 'Yan Daba'. Interview Conducted with the Special Adviser to the Governor of Kano State on Metropolitan Affairs, 19/9/2002.

Jalingo, A.U. (1986). "Social Stratification and Political Order in Northern Nigeria". Kano Studies, B.U.K., 2 (4): 25-38.

Last, M. (1991). "Adolescents in a Muslim City: the Cultural Context of Danger and Risk" Kano Studies, B.U.K, p. 1-22.

Lee, C.D. (1971). Encyclopedia of Education, 5. U.S.A: U.S.A: Macmillan Co. \& The Free Press. Crowd-Collier Educ. Corp.

Shehu, K.A. (2002). "Response to the Questionnaire on the Prevalence and Causes of the Problem of 'Yan Daba" Interview with the Director of Police Public Relations, Kano State Police Command 20/9/2002.

Wells, K.C. \& Forehand, R. (1985) .“Conduct and Oppositional Disorder'. p. 218-265 in (eds) Bornsteing, P.H. \& Kazdin, A.E. Handbook of Clinical Behaviour Therapy with Children. Illimois: The Dorsey Press. 